\title{
The Effect of N-butyl-2-Cyanoacrylate on Wound Healing in the Head and Neck Region
}

\author{
Zeliha KAPUSUZ1 - Y. Kenan Dağlıoğlu² - Muzaffer Gencer ${ }^{3}$ - Mahmut ÖZKIRIȘ \\ Levent SAYDAM ${ }^{5}$ - Sait Polat ${ }^{6}$ \\ 1 Department of Otolaryngology, Head and Neck Surgery, Bozok University Medical Faculty, Associated Professor - ORCID ID: 0000-0003-4707-5862 \\ 2 Medical Sciences Research and Application Center, Cukurova University, Assistant Professor - ORCID ID: 0000-0003-3140-2937 \\ 3 Department of Anesthesia and Resuscitation Bozok University Medical Faculty, Assistant Professor - ORCID ID: 0000-0002-3324-5106 \\ 4 Department of Otolaryngology, Head and Neck Surgery, Bozok University Medical Faculty, Associated Professor - ORCID ID: 0000-0002-0682-0144 \\ 5 Department of Otolaryngology, Head and Neck Surgery, Bozok University Medical Faculty, Professor - ORCID ID: 0000-0001-7042-611X \\ 6 Department of Histology and Embryology, Cukurova University, Professor - ORCID ID: 0000-0003-1646-8831
}

\begin{abstract}
Objective: The study compares the histological appearances of an induced open wound injury as it heals in rabbits, where healing was assisted by either Batticon (a topical antiseptic solution), or Glubran (a surgical glue).

Materials And Methods: The study protocol was first approved by the Research Ethics Committee of Cukurova University. Twenty-eight rabbits with a weight of between 3 and $4 \mathrm{~kg}$, of female sex, were subjected to handling every day for a fortnight preceding the experimental injury so that they could be behaviourally assessed. Seven of the 28 rabbits acted as controls, with the 21 others put into one of 3 groups, depending on the day they were to be sacrificed. For the control animals, a portion of the external ear was excised and examined histologically alongside the intervention group animals, to allow comparisons to be made. The intervention group underwent exposure of a $1 \mathrm{~cm} 2$ area of epidermis bilater-
\end{abstract}

ally. The resulting open injury was then treated on one side with topical antisepis using Batticon and on the other with the Glubran tissue glue. At days 2, 4 and 6 post-surgery, the rabbits were sacrificed and sections of the open wound were viewed with the electron microscope. The control group was also examined histologically for comparison

Results: The sections from ears treated with Glubran had electron microscopic appearances indicative of more extensive regeneration than those where Batticon was used at days 2,4 and 6 .

Conclusion: The results of the study show that N-butyl-2-cyanoacrylate (Glubran) is suitable for the treatment of open injuries to the head or neck.

Keywords: Open wound, N-butyl-2-cyanoacrylate, regeneration, batticon

\section{Introduction}

N-butyl-2-cyanoacrylate (NBC) can promote regeneration after trauma, inhibit bacterial growth and allow tissues to adhere together (1). Ardis was the first to synthesize alkyl-2-cyanoacrylates, in 1949 (2), but it was left to Coo- ver in 1959 to report on their suitability as adhesives (3). The cyanocrylate adhesives differ solely in terms of their side chains, which may consist of various moieties, such as methyl, ethyl, butyl, isobutyl or octyl groups (4).

Cyanoacrylates with methyl side chains were discov-
Correspondence: Zeliha KAPUSUZ

Adnan Menderes Bulvarı No: 42 Yozgat/ TURKEY +905336420232

e-mail: drzeliha19@hotmail.com

Received: November 21, 2018; Accepted: February 6, 2019

Online available at: www.entupdates.org 
ered to be toxic to the tissues, leading to their abandonment in clinical usage (5). NBC has bio-compatibility and therefore may be used in closing traumatic injuries.

When NBC is in contact with water or endothelial, mucosal, dermal or bony tissue, or blood, a mildly exothermic polymerisation reaction takes place, yielding cyanoacetate and methanal. The liquid nature of the reagents mean they can disperse over complex surface geometries, allowing for powerful adhesive bonds to form (6-8).

NBC forms a polymer quickly once exposed to live tissues and if water is present, resulting in the formation of a film with great ability to resist tensile forces, keeping the tissues securely bonded to each other. The process naturally follows the wound contours, resists water, and neither blood nor other fluids prevent bond formation.

The present study aimed to evaluate NBC as a surgical adhesive, from the point of view of how it prevents the entry of pathogenic organisms, by means of an experimental model of wound healing on the head and neck and employing electron microscopy for histopathological assessment.

\section{Materials And Methods}

Twenty-eight rabbits with a weight of between 3 and $4 \mathrm{~kg}$, all female and of New Zealand breed, were subjected to handling every day for a fortnight preceding the experimental injury so that they could be behaviourally assessed. The care and use of the rabbits was in strict accordance with the institutional, national and international protocols pertaining to the experimental use of laboratory animals.

Seven animals formed the controls. The remaining 21 rabbits were allocated at random to one of three groups, depending on the day they were to be sacrificed. Prior to anaesthetic induction, $1 \mathrm{~mL}$ atropine was administered subcutaneously for antispasmodic and anticholinergic effect (atropine sulphate $1 / 2 \mathrm{mg} \cdot \mathrm{mL}^{-1}$, Galen Pharmaceuticals, Istanbul, Turkey). Anaesthesia was achieved by means of intramuscular ketamine hydrochloride (Ketasol, Richter Pharma AG, Wels - Austria) at a dose of $50 \mathrm{mg} \cdot \mathrm{kg}^{-1}$ alongside xylazine $5 \mathrm{mg} \cdot \mathrm{kg}^{-1}$ (Rompun, Bayer Company, Istanbul, Turkey).

Sections from the outer ear of the control group animals were obtained and sent for histological processing to allow comparisons between healthy and traumatised tissue to be made. For the intervention group, a $1 \mathrm{~cm}^{2}$ area of epidermis was resected bilaterally to act as a model for open trauma.
The resected area was treated unilaterally with a topical antiseptic liquid (Batticon ${ }^{\circledR}$ solution 5\%; Adeka, Samsun, Turkey) and contralaterally by closure of the wound with NBC (Glubran 2, GEM Company, Italy). The intervention group animals were then sacrificed at specific intervals: at day 2, 4 and 6. Electron microscopic examination was used to examine differences between the two treatments and to compare both with the control group appearances.

\section{Surgical technique:}

Following anaesthesia, each rabbit was put into the lateral decubitus position and the fur trimmed from the pinna bilaterally. A $1 \mathrm{~cm}$ by $1 \mathrm{~cm}$ area was excised bilaterally from this region, thus forming the model of open trauma. On each animal's right side, $6 \mu \mathrm{L}$ of topical disinfectant (Batticon ${ }^{\circledR}$ solution 5\%; Adeka, Samsun, Turkey) was dropped onto the wound via a sterile micropipette (Eppendorf ${ }^{\circledR}$, Incekaralar Company, Turkey) using sterile technique. The left excised area was coated with $6 \mu \mathrm{L}$ of NBC (Glubran 2, GEM Company, Italy) with identical sterile precautions to the right side. A warming pad was used for the animals to recover after surgery was completed. They were observed postsurgically in case of exhibiting signs of distress, manifesting as alterations in grooming, social behaviour, or changes in body weight. The traumatised area was assessed on days 2, 4 and 6 after the operation. Sections were obtained at these points to assess histologically, including with the transmission electron microscope.

\section{Tissue Preparation Methods for Electron Micros- copy}

A sample of tissue of around $1 \mathrm{~mm}^{3}$ was fixed by insertion in glutaraldehyde $5 \%$ with Millonig's phosphate buffer, keeping the tissue at a temperature of $4^{\circ} \mathrm{C}$ for a 4 -hour period. Millonig's phosphate buffer was then used to rinse the sample. For the next step in fixation, the sample was immersed in $1 \%$ osmium tetroxide plus Millonig's phosphate buffer at a temperature of $4^{\circ} \mathrm{C}$ for a 4 -hour period. The sample was then dehydrated prior to fixation in Araldite $\AA$, and preparation of blocks. A Reichert Ultracut S ultramicrotome was used to cut semi-thin sections for Toluidine blue staining and light microscopic evaluation. A selection of representative areas was then selected and $50 \mathrm{~nm}$ sections produced, which were stained with uranyl acetate and lead citrate. A Jeol JEM 1400 transmission electon microscope was used to produce micrographs serially. 


\section{Results}

\section{Control Group Animals}

The sections obtained from the control rabbits exhibited a normal histological appearance on electron microscopy, revealing keratinised squamous epithelium with stratification and normal basal lamina. The keratinocytes towards the upper surface showed the presence of desmosomal connections and centrally-positioned, mildly indented nuclear outlines. Tonofilaments were abundant within the keratinocyte cytoplasm.

The normal tissue morphological features, i.e. epidermis with underlying dermis, containing abundant hair follicles and sebaceous glands, collagen and elastin fibres in random orientation, small calibre blood vessels and the branched ends of nerve fibres were all observed to be present (Figure 1).

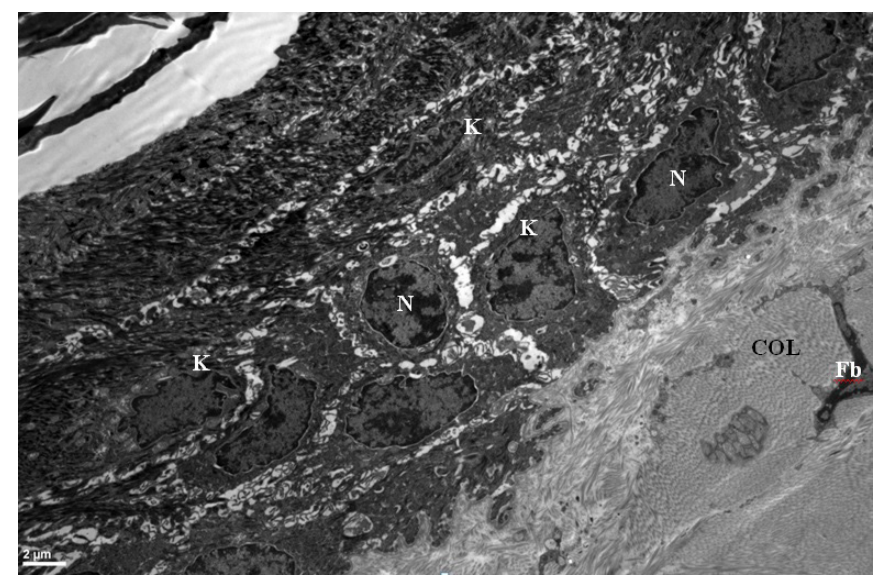

Figure 1. Control group.

Normal histological appearances showing stratified squamous epithelium of keratinising type with dermal fibroblasts (Fb) and randomly oriented collagen fibres. Kaeratinocyte (R), Nucleus (O). Scale bar: 2 microns.

\section{Intervention group}

\section{Rabbits treated with topical antiseptic solution}

Sections of traumatised skin were examined using the electron microscope on Day 2. The sections contained areas of intact epidermis, with stratified, squamous epithelium of keratinised type around the periphery of the lesioned area. Epidermis was missing over the traumatised area and there were homogeneous-appearing exudates present in the wound crater, with cellular fragments apparent resulting from cytolysis, macrophages and erythrocytes in evidence and collagen fiber deposition (Figure 2).

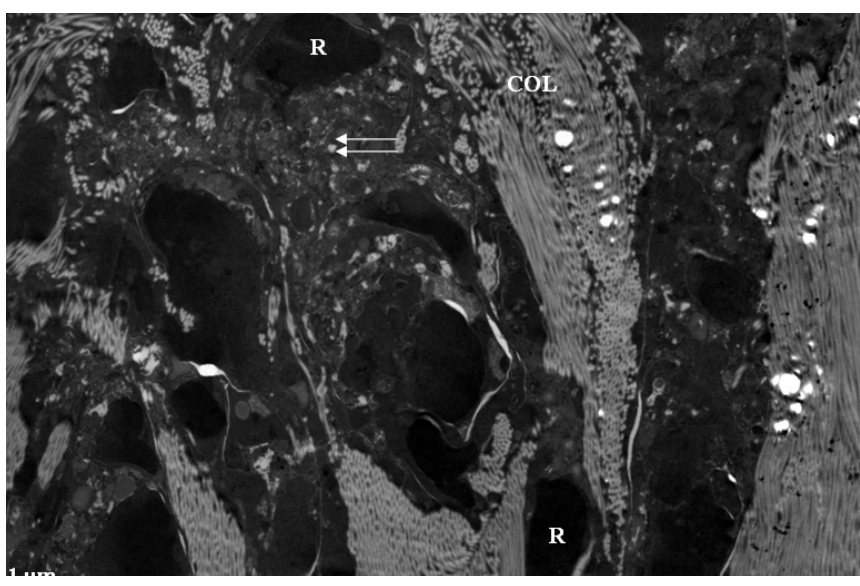

Figure 2. Histological appearances at day 2, topical antiseptic application. Epithelial cells are absent in the upper portion of the wound. A homogeneous exudate is seen. Cytolytic detritus is ubiqitous (double arrow). Macrophages are present, as are erythrocytes (RBC) and collagen fibre formation (Col) deep within the wound.

Sections from the animals sacrificed on day 4 were also viewed with the electron microscope, revealing once again absent epidermis over the traumatised area but margins containing normal type stratified squamous epithelium with keratinisation. Homogeneous exudates were also observed. In the dermis below the injury there were macrophages producing lysosomes, erythrocytes and collagen production. Fibroblasts showed reactive changes, with expansion of the perinuclear cisterns of the endoplasmic reticulum evident.

Sections from the animals sacrificed on day 4 were also viewed with the electron microscope. The traumatized areas taken from this group and the untreated animal tissues were similar to specimens taken at the second and fourth days for the experiment. Samples that were obtained from the border of the traumatized skin areas, showed similar structures to those seen in the control animals. They were both covered by keratinized stratified squamous epithelial cells. The sections showing the dermis contained abundant macrophages, fibroblasts, collagen fibers and multiple erythrocytes. Exudate was apparent in both areas. (Figure 3).

Glubran groups' electron microscopic examination of skin sections, from the end of the 2 days, intact skin around the wound were similarly morphologic appearance to electron microscopic examination of skin sections, from the end of the 2 days of treated group with topical antiseptic solution and control group, is covered by keratinized stratified squamous epithelial cells, plenty of dermal collagen fibers, fibroblasts and macrophages observed in dermis below parts of the epidermis. 


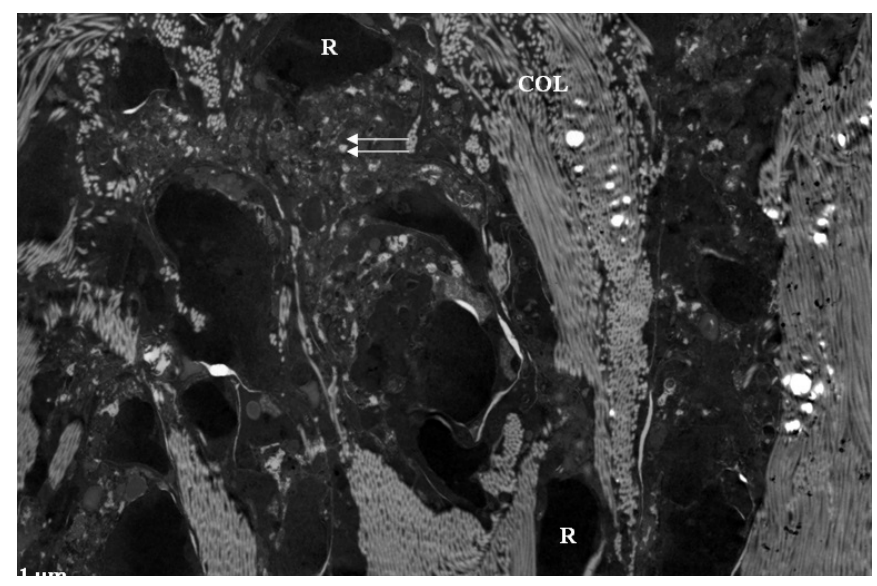

Figure 3. Histological appearances at day 6, topical antiseptic application. Portions of intact skin with the electron microscopic appearance of unlesioned tissue is evident. Note stratified squamous epithelium of keratinising type. Cytolysis is ubiquitous within the trauma area (white arrow). Scale bar: 0.2 microns. Keratinocyte (K), core (C), dermis (D).

Parts of the upper part of the wound near the intact skin areas where the two layers of epithelial cells, plenty of lytic cellular debris, macrophages, red blood cells and collagen fibers in the lower parts of the wound was observed (Figure 4).

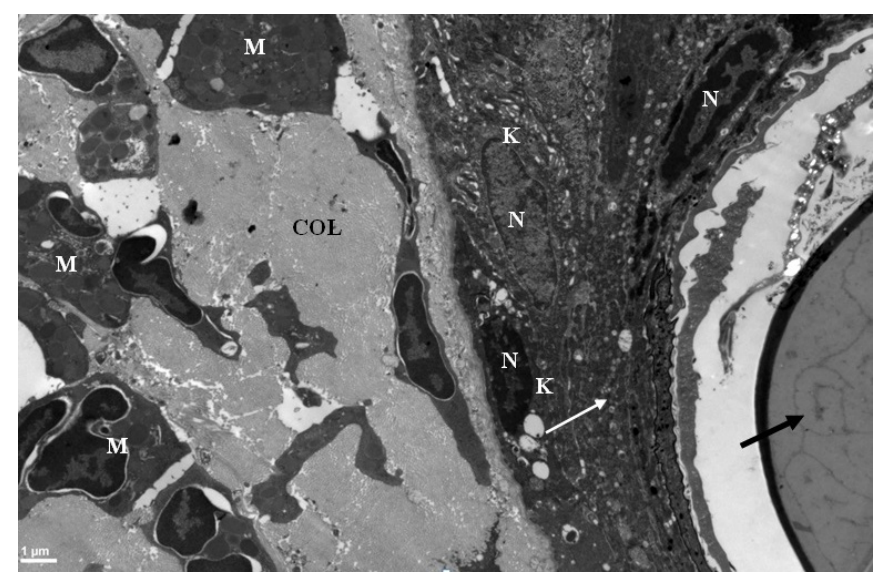

Figure 4. Histological appearances at day 2, NBC group.

Note areas of intact skin in unlesioned area. Double layer of epithelial cells (white arrow). Abundant macrophages are deep within the wound (M). Collagen is being formed. Keratinocyte (K), core (C). Adhesive (black arrow). Scale bar: 1 micron.

After 4 days the animals belonging to the group Glubran 2 electron microscopic examination of the skin sections, sections of intact skin around the wound similarly to the control group, were covered by keratinized stratified squamous epithelial cells. Parts of intact skin near the wound parts of the upper part, similar to Glubran 2 tissues from the animals after 2 days, two or three times with epithelial cells, where the lower part of the wound created in the dermis of the lytic abundant cell debris, macrophages, red blood cells, fibroblasts and collagen fibers was received.

After 6 days the animals belonging to the group Glubran 2 electron microscopic examination of the skin sections, parts of the intact skin around the wound similarly to the control group, were found to be covered by keratinized stratified squamous epithelial cells (figure 5). Parts of the upper part of the wound close to intact skin areas, Glubran 2 the tissues taken from animals 2 and 4 days later, similar to a two-layer epithelial cells, the wound in the lower part of the earth was created in large amounts in the dermis lytic cell debris, macrophages, erythrocytes, fibroblasts and collagen fibers were received.

\section{Animals treated with NBC}

The microscopic examination of sections obtained on day 6 produced similar findings to those at days 2 and 4, i.e. margins of normal skin appearance surrounding the area of injury, which was characterised by an homogeneous exudate with plentiful macrophages, erythrocytes, fibroblasts and new collagen fiber formation. In the area where the epidermis had been excised, there was an homogeneous exudate with macrophages producing lysosomes, evidence of cytolysis, proliferating collagen formation by fibroblasts and frequent erythrocytes (Figure 4).

The histological appearances at day 4 of the animals treated with NBC did not differ greatly from those observed at day 2 for animals in the same group.

At day 6, the sections from the NBC-treated rabbits had areas of intact skin around the wound with normal squamous stratified epithelium of keratinised type. The (Figure 5). The traumatised area had the following characteristics: exudate with cytolytic cellular remnants, macrophages, erythrocytes and collagen formation.

The border area of intact skin around the wound showed similar structure, i.e. a dual layer of epithelial cells. The traumatised area was characterised by lytic cell debris, macrophages, erythrocytes, fibroblasts and collagen fibers observable in the central part of the lesion.

\section{Discussion}

Although trauma management and wound care have now greatly advanced, infected trauma remains a principal reason for death, morbidity and economic hardship for mil- 


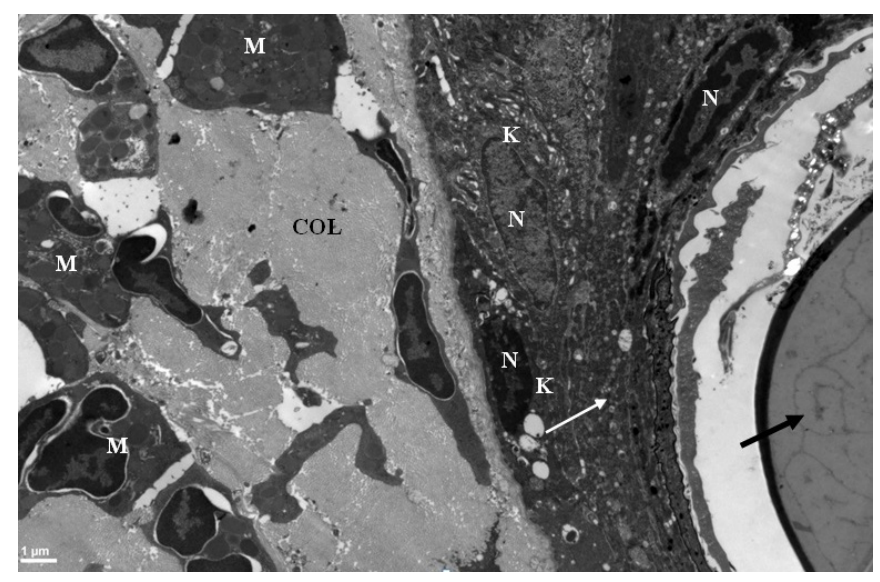

Figure 5. Histological appearances at day 6, NBC group. Note areas of intact skin in unlesioned area. Double layer of epithelial cells (white arrow). Cellular debris lies deep within the wound (black arrow). Keratinocyte (K), core (C). Adhesive (black arrow). Scale bar: $2 \mathrm{~mm}$.

lions of individuals worldwide (9-15). Trauma is defined as an injury occasioning breakage of an intact bodily tissue, whether externally visible or internal. Open trauma involves a discontinuity in a mucosal or epidermal external surface. The application of dressings may present difficulties, particularly on the proximal limbs and over the body. Undressed wounds are more prone to bacterial contamination, leading to retarded tissue regeneration. Whilst topical application of antibacterial agents might reduce infection and colonisation by bacteria, hypersensitivity can develop from overuse $(9,10)$.

Trauma to the skin initiates a cascading series of processes with the final goal of tissue regeneration. The classical division of the processes involved is into three phases: inflammatory, granulation and fibrotic remodelling phases. There are a wide variety of cell types, enzymes, cytokines, endocrine factors and ions that play key roles. Areas of skin breakage may be treated surgically with suturing or glue (16), the aim being to oppose the wound edges so as to close the wound and allow regeneration to occur without excessive scar formation. Surgical adhesives offer the possibility of preventing entry of microorganisms and promoting well-regulated tissue regeneration.

A number of different pathogenic infections may occur after trauma or post-surgically. Such infections impair wound healing, leading to prolonged time to regenerate and exposing the patient to a greater risk of scarring.

A number of agents have been proposed for use in wound care. One such is povidone-iodine, which has pro- ven efficacy against a multitude of pathogenic organisms: bacteria, yeast, moulds, viruses, fungi, protozoa, actinomycetes and rickettsia, at least in vitro. Due to this profile, povidone-iodine has found great favour in surgical use for handwashing before surgery, cleaning the skin before and after operations and to manage potential infection in wounds, ulceration, laceration and burn injury (17).

NBC-type surgical glues are another option. They can promote haemostasis in peripheral vasculature to an impressive degree $(6,18-22)$. By closing wounds, they can prevent seepage from the lymphatics. Due to their ability to form an impassable barrier, cyanoacrylates allow wounds to be closed once, without the need to monitor their progress (22).

Since cyanoacrylates are naturally eliminated by the body in under a week after their use, foreign body-type reactions are not seen in surrounding tissues $(6,23,24)$. Gonzalez et al. (25) see the lack of foreign body reaction and non-infection as evidence of the cyanoacrylates' being highly biocompatible and achieving bacteriostasis.

A study of the antibacterial effectiveness of cyanoacrylate indicated that Gram-positive bacteria (Staphylococcus aureus and Streptococcus pneumoniae) were inhibited to a greater extent than the Gram-negative bacteria used in the study (Escherichia coli and Pseudomonas aeruginosa) (26). Eiferman et al. noted that cyanoacrylates failed to produce a zone of inhibition with Klebsiella pneumoniae, a Gram-negative bacteria that ressembles E. coli (27). Bacteriostasis was seen with methoxypropyl or N-butyl cyanoacrylate and $S$. aureus, S. pneumoniae, and Mycobacterium chelonae, however, neither P. aeruginosa nor E. coli were susceptible (28). The topical use of other microbials in conjunction with cyanoacrylates is a potential way around this difficulty.

Some research has also shown that traumatised corneal stroma benefits from cyanoacrylate treatment, leading to improved regenerative capabilities, new vessel formation and re-epithelialisation (29). There was the additional advantage that corneal tissues were not dissolved, since the adhesive inhibited the action of collagenase enzymes and prevented inflammatory cell infiltration by granulocytes.

To conclude, there are several reasons why cyanoacrylate adhesives find favour clinically: they improve cosmetic outcomes, lessen the risk of morbidity, do not call for local anaesthetic usage in their application, are routinely eliminated (in a 5 to 10 day window), form a barrier to bacterial entry into wounds $(31,32)$ and take less time to employ than suturing $(6,18)$. 
Thus, such surgical adhesives mean limited areas of trauma that are external and not deep can be easily, rapidly and comfortably closed.

Our study has shown that NBC leads to reduced inflammatory reaction in the regeneration of tissue injury compared to wounds treated only with the application of a topical antiseptic (i.e. Batticon). This supports the benefits of the adhesive in treating open injury. The authors pro-

\section{References}

1. McKinley SH, Yen MT (2005) Octyl-2-cyanoacrylate tissue adhesive in external dacryocystorhinostomy. Ophthal Plast Reconstr Surg 21(3):197-200

2. Ardis AE. U.S. Patents No. 2467926 and 2467927(1949).

3. Coover HW, Joyner FB,Shearer Jr NH, Wicker Jr TH. Chemistry and performance of cyanoacrylate adhesive. J Soc Plast Eng. 1959;15:41317.

4. Toriumi DM, Raslan WF, Friedman M, Tardy E. Histotoxicity of cyanoacrylate tissue adhesives. A comparative study. Arch Otolaryngol Head Neck Surg. 1990;116:546-50.

5. Straatsma BR, Allen RA, Hale PN, Gomez R. Experimental studies employing adhesive compounds in ophthalmic surgery. Trans Am Acad Ophthalmol Otolaryngol. 1963;67:320-34.

6. Giray CB, Sungur A, Atasever A, Araz K. Comparasion of silk sutures and n-butyl-2-cyanoacrylate on the healing of skin wounds. A pilot study. Aust Dent J. 1995;40:43-5.

7. Weber SC, Chapman MW. Adhesives in orthopedic surgery a review of the literature and in vitro bonding strengths of bone-bonding agents. Clin Orthop. 1984;191249-56.

8. Shermak MA, Wong L, Inoue W, Crain BJ, Im MJ, Chao EY, et al. Fixation of the craniofacial skeleton with butyl-2-cyanoacrylate and its effect on histotoxicity and healing. Plast Reconstr Surg. 1998;102:309-18.

9. Pruitt BA, Jr, McManus AT, Kim SH, Goodwin CW. Burn wound infections: current status. World J Surg. 1998;22:135-145.

10. Murray CK. Infections in burns. J Trauma. 2007;62:73.

11. Cheadle WG, Turina M. Infection and organ failure in the surgical patient: a tribute to seminal contributions by Polk HC Jr. Am J Surg. 2005;190:173-177.

12. Sebeny PJ, Riddle MS, Petersen K. Acinetobacter baumannii skin and soft-tissue infection associated with war trauma. Clin Infect Dis. 2008;47:444-449.

13. Evans RP. Surgical site infection prevention and control: an emerging paradigm. J Bone Joint Surg Am. 2009;91:2-9.

14. Neubauer T, Bayer GS, Wagner M. Open fractures and infection. Acta Chir Orthop Traumatol Cech. 2006;73:301-312.

15. Broex EC, van Asselt AD, Bruggeman CA, van Tiel FH. Surgical site infections: how high are the costs? J Hosp Infect. 2009;72:193-201.

16. Kawai K, Larson BJ, Ishise H, Carre AL, Nishimoto S, Longaker M, Lorenz HP.Calcium-based nanoparticles accelerate skin wound healing. PLoS One. 2011;6(11):e27106. Epub 2011 Nov 2 pose that NBC glues are suitable to treat trauma involving breaches of the skin on the head and neck. So far as the authors are aware, this study is the first to systematically evaluate by means of histopathological analysis the effect of NBC on an injury in the head and neck region. This is of especial clinical significance given the high potential for disfigurement in the head and neck region.

17. Jayaraj KK, Jayachandran E, Gridhar B, Nair R, Jayakandan M, Kathiravan M, Srinivas GMl. Formulation and evaluation of povidone iodine liquid anti-dandruff shampoo. J Pharm Sci\& Res 2009; 1: 108-11.

18. Pérez M, Fernandez I, Márquez D, Bretaña RMG. Use of n-butyl-2-cyanoacrylate in oral surgery: biological and clinical evaluation. Artif Organs. 2000;24:241-43.

19. Al-Belasy FA, Amer MZ. Hemostatic effect of n-butyl-2-cyanoacrylate (histoacryl) glue in warfarin-treated patients undergoing oral surgery. J Oral Maxillofac Surg. 2003;61:1405-09.

20. Dôner F, Sari I. Facial wound closure with butyl 2-cyanoacrylate. J Basic Clin Physiol Pharmacol. 2003;14:359-71.

21. Camacho-Alonso F, Lopez-Jornet P, Bermejo- Fenoll A. Effects of scalpel (with and without tissue adhesive) and cryosurgery on wound healing in rat tongues. Oral Surg Oral Med Oral Pathol Radiol Endod. 2005; 100:58-63.

22. Turkaslan T, Ozcan H, Dayicioglu D, Ozsoy Z. Use of adhesives in cleft palate surgery: a new flap fixation technique. J Craniofac Surg. 2005; 16:719-22.

23. Reece TB, Maxey TS, Kron IL. A prospectus on tissue adhesives. Am J Surg. 2001;182:40S;4S.

24. Choi HB, Kim BY, Huh JY, Lee SH, Zhu SJ, Jung JH, et al. Microneural anastomosis using cyanoacrylate adhesives. Int J Oral Maxillofac Surg. 2004;33:777; 80 .

25. Caroli A, Marcuzzi A, Limontini S, Maiorana A. An experimental study of a cyanoacrylate biological adhesive in view of its use in the fixation of various fractures of the fingers. Ann Chir Main Memb Super. 1997;16:138-45.

26. Gonzalez E, Orta J, Niemshik L, Galera R, Onay R, Rojas O. Ethyl-2-cyanoacrylate fixation of the cranial bone flap after craniotomy. Surg Neurol. 2000;53:288-89.

27. Ivana L Romero, João B N S Malta, Cely B Silva, Lycia M J Mimica, Kaz H Soong, and Richard Y Hida. Antibacterial properties of cyanoacrylate tissue adhesive: Does the polymerization reaction play a role?Indian J Ophthalmol. 2009 Sep-Oct; 57(5): 341-344.

28. Eiferman RA, Snyder JW. Antibacterial effect of cyanoacrylate glue. Arch Ophthalmol. 1983;101:958-60.

29. Chen WL, Lin CT, Hsieh CY, Tu IH, Chen WY, Hu FR.Comparison of the bacteriostatic effects, corneal cytotoxicity, and the ability to seal corneal incisions among three different tissue adhesives. Cornea. 2007 Dec;26(10):1228-34. 
30. Sharma A, Kaur R, Kumar S, Gupta P, Panda V S, Patnaik B, et al. Fibrin glue versus N-butyl-2-cyanoacrylate in corneal perforations. Ophthalmology. 2003;110:291-8.

31. Refojo MF, Dohlman CH, Ahmad B, Carrol JM, Allen JC. Evaluation of adhesives for corneal surgery. Arch Ophthalmol. 1968;80:645-56.

32. Goktas N, Karcioglu O, Coskun F, Karaduman S, Menderes A. Com- parison of tissue adhesive and suturing in the repair of lacerations in the emergency department. Eur J Emerg Med. 2002; 9:155-8.

33. Pelissier P, Casoli V, Le Bail B, Martin D, Baudet J. Internal use of n-butyl 2-cyanoacrylate (Indermil) for wound closure: an experimental study. Plast Reconstr Surg. 2001;108:1661-6.

This is an open access article distributed under the terms of the Creative Commons Attribution-NonCommercial-NoDerivs 3.0 Unported (CC BY- NC-ND3.0) Licence (http://creativecommons.org/licenses/by-nc-nd/3.0/) which permits unrestricted noncommercial use, distribution, and reproduc- tion in any medium, provided the original work is properly cited.

Please cite this article as: Kapusuz Z., Dağlığlu Y.K., Gencer M., Özkırış M., Saydam L., Polat S., The Effect of N-butyl-2-Cyanoacrylate on Wound Healing in the Head and Neck Region. ENT Updates 2019;9(1): 18-24 